\title{
Research on the Application of Cultural Element of Guangxi Minorities in Modern Landscape Design
}

\author{
Dujiang Long \\ Guilin Institute of Tourism, 541000 Guilin Guangxi, China
}

\begin{abstract}
There are 11 Minorities in Guangxi, and the cultural ethnics among each minority are varied to a certain extent. Despite the difference, each minority has made contributions to the Chinese civilization. Guangxi is a region teeming with minorities. The difference of minorities comprises the type of local cultural element. In the process of modern landscape design, the incorporation design or cultural elements for relevant staff are required. And it is the infiltration of these cultural elements that press ahead the landscape design. For people to discover the cultural source, and for the soul to find the spiritual sense of belongings, this article has made a research on the features of Guangxi minorities cultural elements and the application in landscape design, expecting to provide a theoretical reference for incorporation of cultural element and productive construction.
\end{abstract}

Keywords. cultural element; Guangxi minorities; minorities landscape design; derivative and reconstruction

\section{Introduction}

Lu Zongye, etc. (2014) proposed that, in Chinese economic transformation period, the method to improve the status of culture industry in development of national economy has become the concentrated subject for Party Central Committee in 12th Five-Year Plan. With the commencement of system reform of cultural units, the creation mode of culture products oriented by market demand has gradually formed and deeply affected the development of artistic design industry in economic region of Guangxi northwest ${ }^{[1]}$. Guangxi is a region teeming with minorities. The difference of minorities comprises the local cultural elements exclusive in this region. If the cultural element can be incorporated into the productive construction, it will satisfy a part of the demand, and serve the people based on the contributions that can be made to the inheritance of ethnic culture. Li Hongjian (2013) proposed that, the cultural element of Guangxi minorities is sole in China or in the world. For a long time, the excellent cultural element is inherited and continued, which incorporates the relatively ethnically characteristic indoor space environment, entertaining space environment, urban landscape, city building and other actual cases to discuss the inheritance of Guangxi ethnic element in modern environmental art $^{[2]}$. Xiao Wanjuan, etc. (2013) proposed that, the garden building is the carrier of culture inheritance, and the research on the application of cultural element of Guangxi Zhuang nationality in region forming is conducive to improveing the landscape characteristics of garden building, strengthening the sense of belongings and identity and promoting the cultural deposits and general image of city. She proposed to use the multiple methods to decorate the surface of garden building, form the shape of garden building with traditional and modern texture shaping and continue the connotation of garden building environment of Zhuang nationality with original space in Zhuang nationality, expecting to provide the reference basis for the shaping of region characteristics of garden buildings. ${ }^{[3]}$

This article discusses the application of cultural element of Guangxi minorities in the modern landscape design based on the predecessors' researches, expecting to provide a guidance ideology for incorporation of cultural element into the production construction, and a theoretical basis for landscape design idea with ethnic and cultural characteristics.

\section{Analysis on the relation of cultural el- ement and landscape design}

Zhang Jing, etc. (2014) proposed that, with the development of era, the relation of Chinese traditional culture and design has gradually become the concentrated problem for designers. Multiple traditional cultures have been applied by the landscape designers in the modern garden landscape design, and meanwhile incorporated into the whole style to form a organic whole ${ }^{[4]}$.

The reformation and application of traditional cultural element in the current design process, plus the un- 
derstanding of manifestation of traditional culture, will endow the works with cultural spirit connotation and the features of era ${ }^{[5]}$. Chinese ideology of classical garden design is broad and profound, which focuses on the ancient philosophical ideology "Nature and Man in One" and the abundance of traditional culture essence. While in the landscape design of modern garden, the Chinese traditional cultural elements are generally used in the construction of residential environment, which is skillfully analogous to the ideology of harmony and uniformity of man and nature ${ }^{[6]}$. Therefore, the essence of Chinese traditional culture has an extremely important effect of inspiration and reference on the modern landscape design. The deep research on the traditional culture is conducive to the historical development and era progress ${ }^{[7]}$. The inheritance and development of Chinese traditional cultural element are closely related in the modern landscape design, and the incorporation of traditional ideology and modern style can create the modern garden landscape environment with Chinese traditional prospect, and finally achieve the goal of developing the design culture with our own traditional style.

The application of the traditional cultural element in modern scenic garden design mainly includes the creation of space, application of traditional colors and traditional symbols, and the configuration of plants. Then, we will analyze the application in the above four aspects, expecting to explore the relation of cultural element and the landscape design, and meanwhile provide a theoretical reference for the application of cultural element of Guangxi minorities in the modern landscape design.

1) Creation of space: obstructive and divisive view, borrowing and receiving view, simulation and miniature view, enframed and leaking view, and other methods of classic garden jujube orchard are often used in the modern garden landscape, expecting to achieve the space effect of moving with changed view and seeing much in little. Meanwhile, we can add the modern element in the design process in a way of "incorporation of ancient and modern element" to jointly create a space environment with layers, and to form a landscape venue with Chinese traditional cultural features and atmosphere. Empirical true-and-false application case of enframed view as shown in Figure 1.

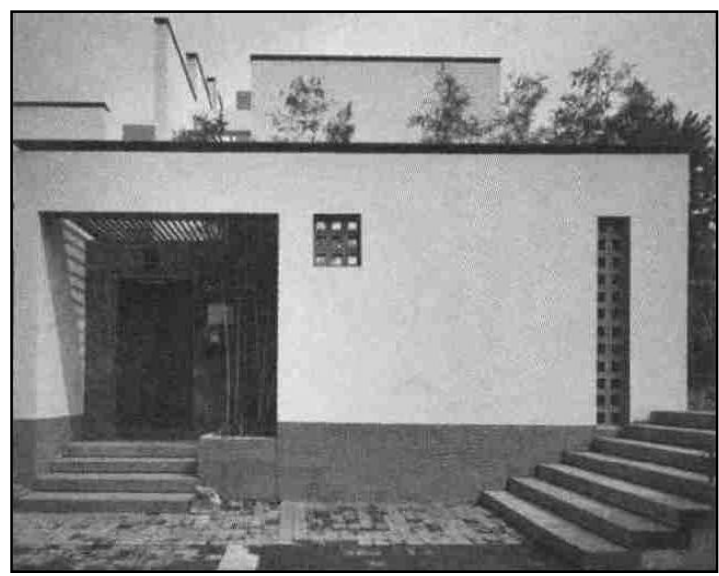

Figure 1. Empirical true-and-false application case of enframed view.

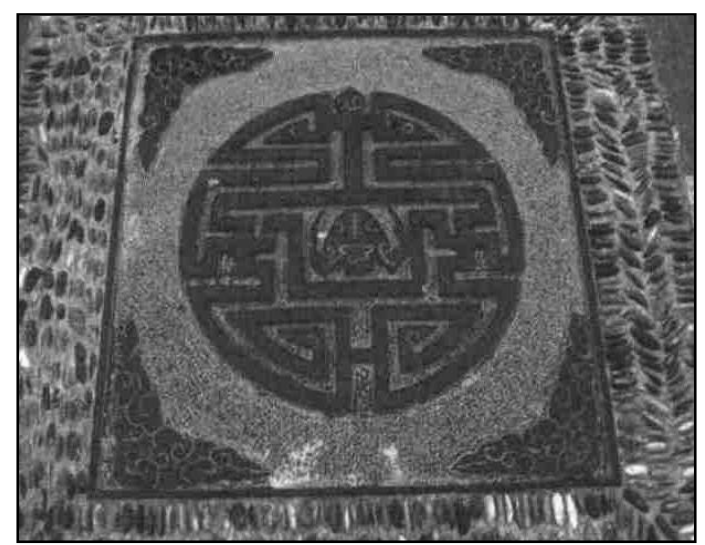

Figure 2. Empirical application case of Auspicious clouds pattern.

2) Application of traditional colors: The concentration colors representing the Chinese civilization mainly includes the Chinese red, yellow, blue and white on blue, jade rouge white, stone gray, green, etc. If the material and new Chinese style positioning are incorporated, we usually use the wood color and black, which will jointly create the landscape expression, and may present the cultural landscape atmosphere of happiness, harmony, tranquility and introversion. For example, the Vanke V Park incorporates the gray and wood color in pavement, and use reasonable division and matching in patterns to achieve the harmony and uniformity. The black flower pond, white wall surface and part of the pavement comprise the tranquil and pure space.

3) Application of traditional symbols; The Chinese traditional mascots includes Tsing lung, white tiger, rose finch, tortoise, grass tortoise, Pi Xiu, etc., as well as metal, wood, water, fire, earth, Zhouyi and geomancy theories. Plus, China has many patterns with ethnic characteristics: such as paper cut, dragon and phoenix pattern, auspicious cloud pattern, Chinese knit, embroidery, etc., as well as traditional dignified plants plum blossoms, orchid, bamboo, chrysanthemum, peony, lotus, pine, cypress, etc. These traditional cultural symbols are often abstracted or simplified as the design elements in the modern design. Empirical application case of auspicious patters is as shown in Figure 2.

4) Configuration of plants: The plants are important for the garden landscaping, and one of the essences for garden landscape, which can create the space environment of appreciation and tourism for people, and meanwhile improve the little climate and living environment. Chinese classic garden, apart from the potting plants, requires no reshaping, and themed with the natural shape and colors. While in the modern garden design, the kinds of plants are increased with reduced layers by combination of reshaped bush and natural type plantation.

In summary: The cultural element is significant in the modern landscape design, which can improve the aesthetics, produce the cultural sense of belongings. Currently, China is in the era of opening policy to inherit the past tradition and forge ahead into the future, so it is required to introduce the western design idea and incorporate the local cultural element to finally achieve the sustainable development. 


\section{Features of the incorporation of cul- tural element of Guangxi minorities with modern landscape design}

Zhang Ming (2010) proposed that, there are 11 minorities in Guangxi with their own ethnic culture and folk arts with long history, where the excellent cultural elements are being constantly inherited and continued for a long time, and affected the building, garden, artistic creation and sculpture in modern city. These cultural symbols with traditional regional features impress the modern civilization with special signs through hundreds, thousands and even millions of years of inheritance ${ }^{[8]}$.

The cultural element of Guangxi minorities is exclusive in China and even in the world. Since the opening up policy, the patterns, textures, etc. in the ethnic cultural element have been wide applied in the landscape design, as shown in ornamental sculpture of Guangxi Hall in Beijing Great Hall in Figure 3 and ornamental sculpture in the outer wall of Guangxi Great Hall in Figure 4. With the development of era, the society also keeps its pace therewith, and the constant absorption, reference of ethnic cultural element and its deconstruction and reconstruction gradually form a new art. So the research on the deconstruction and combination of cultural element of minorities in modern landscape design is very necessary.

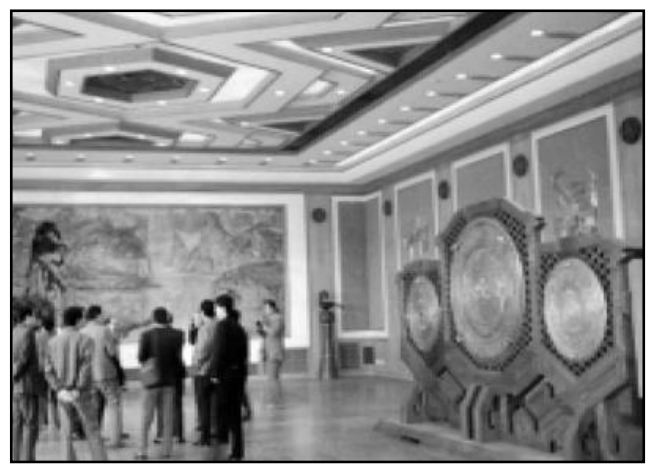

Figure 3. Ornamental sculpture of Guangxi Hall in Beijing Great Hall.

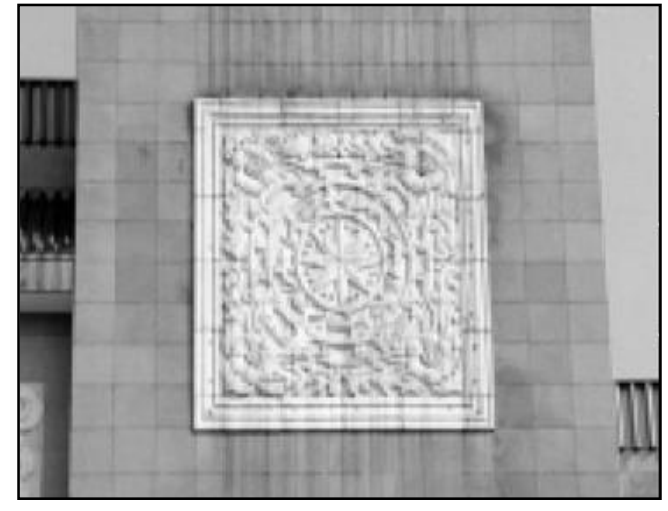

Figure 4. Ornamental sculpture in the outer wall of Guangxi Great Hall.

The features of deconstruction and combination of cultural element in Guangxi minorities and modern landscape design mainly include the subjective epistemology, living practicality, natural simulation and abstracted artistic imagination. It will be described in details as follows:
1) Subjective epistemology: The subjective epistemology refers to one of the most systematic and outstanding representation of the relation between man and nature. It is the man's subjective motility that reforms the nature and creates the harmony and balanced relation for humans, and therefore the arts.

2) Living practicality: The initial human activities must be for the living purpose, which is determined by material civilization of primitive ethnics, and also closely related to the reproduction of human kinds. A fish with raised head and tail was found in the town of Mulao Nationality in Luo City of Guangxi, as the Mulao Nationality is an ethnic that focuses on belief. To worship the god, prepare a place for offering the sacrifices and prevent the clean wall surface from being damaged, Mulao Nationality designed a most common fish in daily life. The dependence and worship of bronze drum of Zhuang minorities can be found in the bronze drum. The corresponding shape of sun pattern, frog, dancing of feather man, dragon ball race and other patterns and gingerbread commonly seen in the drum can also be found in the life of Zhuang nationality.

3) Natural simulation: The art of Guangxi minorities is more close to the nature, while the simulation of creatures in nature is their main source of artistic creation, such as flower and patters on the back of Miao Nationality women, which are all sourced from the simulation of nature. Rose, Begonia, morning glory, peach blossom and other common flowers are impressive to people, which are handy and available in the creation of garments. The combination of rich and colorful butterflies makes abundance and beautifulness.

4) Abstractive artistic imagination: The abstractive ability is one of the physiological functions special for humans as indicated by modern psychology and physiology. In human long-term culture evolution, the abstractive function has gradually become one of the people's aesthetic abilities. Driven by this mentality and integrated by aesthetic ability, the abstractive structure becomes a exploring desire in people's heart. Rhythm, order sense, balance, proportionate and other mental factors also perfect the abstractive aesthetic art.

In summary: The ethnic art and ethnic cultural element created by Guangxi shall be protected, inherited and developed. We shall deeply understand the cultural element in Guangxi minorities, and incorporate it with modern ideology, meanwhile carry out deconstruction and combination to develop and improve the modern and traditional cultures, and to use the traditional Guangxi cultural element for serving the construction of modern Guangxi culture.

\section{Discussion on the application of cultural element of Guangxi Zhuang Nationality in modern landscape design}

Based on cultural element of Guangxi Zhuang Nationality, the elements shall be refined, and constantly dissolved, transformed, reconstructed and incorporated into a new design to endow the shape and ornaments with rich features cultural connotation of Zhuang nationality. As 
known from the evolution process of big-leaf hydrangea-$>$ petal pattern--> garden pavement, the landscape design can derive and reconstruct the cultural element of Zhuang nationality in vertical and horizontal thinking, namely a cultural element can use multiple landscape design, and one landscape design can be created by multiple cultural elements. The application type mainly includes the ornamental decoration and shaping of garden building ${ }^{[9]}$.

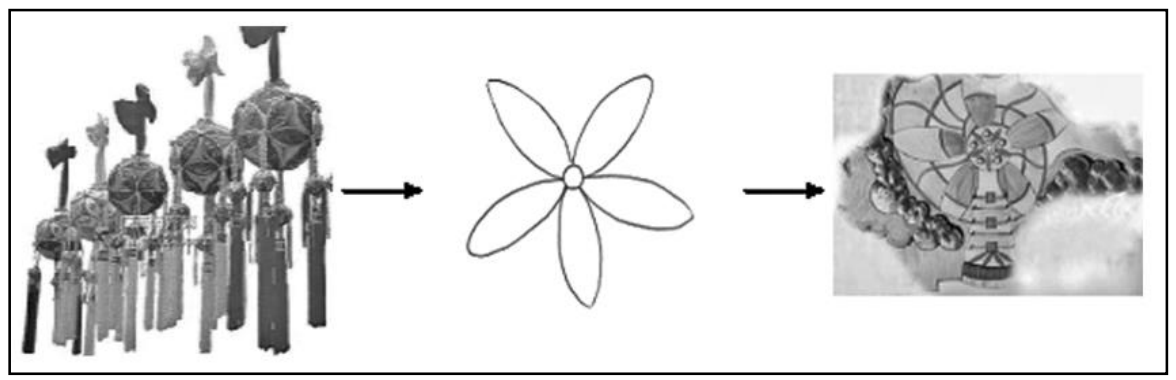

Figure 5. Diagram of evolution process of big-leaf hydrangea--> petal pattern--> garden pavement.

Arrange the A1 natural cultural element, A2 material cultural element and A3 spirit cultural element refined in vertical thinking in the process of modern landscape design. Among which: The natural cultural element includes A11 local material, including wood, stone, etc., A12 animals includes frog, cattle, bird, cock, etc.; Material cultural element includes A21 pattern ornament, A22 artificial structure, A23 production tools, A24 machining tools, A25 fishing tools, A26 colors, A27 words, A28 instruments; Spirit cultural element includes A31 behavioral activities, A32 astral worship, A33 silent worship,
A34 animal worship, A35 figure worship, A36 legends, etc.. B1 pavilion, B2 corridor, B3 gate, B4 stall, B5 flower stand, B6 round stool, B7 sculpture, B8 rail, B9 scenic lamp, B10 lighting post, B11 signboard, B12 dustbin, B13 flowerpot, B14 vehicle barricade post, B15 scenic wall and other garden buildings that are applied in horizontal thinking construction criss-cross each other and vividly present the interrelationship among various element languages and garden buildings. Derivation and reconstruction of Zhuang nationality cultural element in landscape design application as shown in Table 1.

Table 1. Derivation and reconstruction of Zhuang nationality cultural element in landscape design application.

\begin{tabular}{lllllllllllllllll}
\hline Type & Subject & B1 & B2 & B3 & B4 & B5 & B6 & B7 & B8 & B9 & B10 & B11 & B12 & B13 & B14 \\
\hline \multirow{2}{*}{ A1 } & A11 & $\sqrt{ }$ & $\sqrt{ }$ & $\sqrt{ }$ & $\sqrt{ }$ & $\sqrt{ }$ & $\sqrt{ }$ & $\times$ & $\sqrt{ }$ & $\sqrt{ }$ & $\times$ & $\times$ & $\times$ & $\times$ & $\times$ \\
& A12 & $\times$ & $\times$ & $\times$ & $\sqrt{ }$ & $\times$ & $\sqrt{ }$ & $\sqrt{ }$ & $\sqrt{ }$ & $\sqrt{ }$ & $\times$ & $\sqrt{ }$ & $\sqrt{ }$ & $\sqrt{ }$ & $\times$ \\
& A21 & $\times$ & $\times$ & $\sqrt{ }$ & $\sqrt{ }$ & $\sqrt{ }$ & $\sqrt{ }$ & $\sqrt{ }$ & $\sqrt{ }$ & $\sqrt{ }$ & $\sqrt{ }$ & $\sqrt{ }$ & $\times$ & $\sqrt{ }$ & $\sqrt{ }$ \\
& A22 & $\sqrt{ }$ & $\sqrt{ }$ & $\sqrt{ }$ & $\sqrt{ }$ & $\sqrt{ }$ & $\times$ & $\times$ & $\times$ & $\times$ & $\times$ & $\times$ & $\times$ & $\times$ & $\times$ & $\times$ \\
& A23 & $\times$ & $\times$ & $\times$ & $\times$ & $\times$ & $\sqrt{ }$ & $\sqrt{ }$ & $\times$ & $\times$ & $\sqrt{ }$ & $\sqrt{ }$ & $\sqrt{ }$ & $\sqrt{ }$ & $\times$ \\
A2 & A24 & $\times$ & $\times$ & $\times$ & $\sqrt{ }$ & $\times$ & $\sqrt{ }$ & $\times$ & $\times$ & $\sqrt{ }$ & $\sqrt{ }$ & $\times$ & $\sqrt{ }$ & $\sqrt{ }$ & $\times$ & $\sqrt{ }$ \\
& A25 & $\sqrt{ }$ & $\sqrt{ }$ & $\sqrt{ }$ & $\sqrt{ }$ & $\sqrt{ }$ & $\sqrt{ }$ & $\sqrt{ }$ & $\sqrt{ }$ & $\sqrt{ }$ & $\sqrt{ }$ & $\sqrt{ }$ & $\sqrt{ }$ & $\sqrt{ }$ & $\sqrt{ }$ \\
& A26 & $\sqrt{ }$ & $\sqrt{ }$ & $\sqrt{ }$ & $\sqrt{ }$ & $\sqrt{ }$ & $\times$ & $\times$ & $\sqrt{ }$ & $\sqrt{ }$ & $\times$ & $\sqrt{ }$ & $\times$ & $\times$ & $\times$ \\
& A27 & $\times$ & $\times$ & $\sqrt{ }$ & $\sqrt{ }$ & $\times$ & $\sqrt{ }$ & $\times$ & $\sqrt{ }$ & $\sqrt{ }$ & $\sqrt{ }$ & $\sqrt{ }$ & $\sqrt{ }$ & $\sqrt{ }$ & $\sqrt{ }$ \\
& A28 & $\times$ & $\times$ & $\times$ & $\times$ & $\times$ & $\times$ & $\sqrt{ }$ & $\times$ & $\sqrt{ }$ & $\times$ & $\sqrt{ }$ & $\times$ & $\times$ & $\times$ \\
& A31 & $\sqrt{ }$ & $\sqrt{ }$ & $\sqrt{ }$ & $\sqrt{ }$ & $\sqrt{ }$ & $\sqrt{ }$ & $\sqrt{ }$ & $\sqrt{ }$ & $\sqrt{ }$ & $\sqrt{ }$ & $\sqrt{ }$ & $\sqrt{ }$ & $\sqrt{ }$ & $\sqrt{ }$ \\
& A32 & $\sqrt{ }$ & $\sqrt{ }$ & $\sqrt{ }$ & $\sqrt{ }$ & $\sqrt{ }$ & $\sqrt{ }$ & $\sqrt{ }$ & $\sqrt{ }$ & $\sqrt{ }$ & $\sqrt{ }$ & $\sqrt{ }$ & $\sqrt{ }$ & $\sqrt{ }$ & $\sqrt{ }$ \\
& A33 & $\times$ & $\times$ & $\sqrt{ }$ & $\sqrt{ }$ & $\times$ & $\sqrt{ }$ & $\sqrt{ }$ & $\sqrt{ }$ & $\sqrt{ }$ & $\sqrt{ }$ & $\sqrt{ }$ & $\times$ & $\times$ & $\times$ \\
& A34 & $\sqrt{ }$ & $\sqrt{ }$ & $\sqrt{ }$ & $\times$ & $\times$ & $\times$ & $\sqrt{ }$ & $\times$ & $\sqrt{ }$ & $\times$ & $\sqrt{ }$ & $\times$ & $\times$ & $\times$ \\
& A35 & $\sqrt{ }$ & $\sqrt{ }$ & $\sqrt{ }$ & $\sqrt{ }$ & $\times$ & $\sqrt{ }$ & $\times$ & $\sqrt{ }$ & $\times$ & $\times$ & $\sqrt{ }$ & $\times$ & $\times$ & $\times$ \\
\hline
\end{tabular}

Any landscape building in the garden landscape has a certain construction way, as shown in the rail ornament of Zhuang brocade in Figure 6 and wall surface ornament of living utensils in Figure 7, which serve as an excellent example.

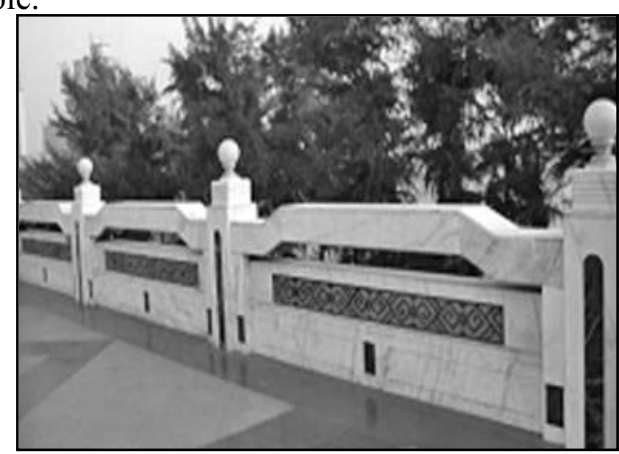

Figure 6. Rail ornament of Zhuang brocade.

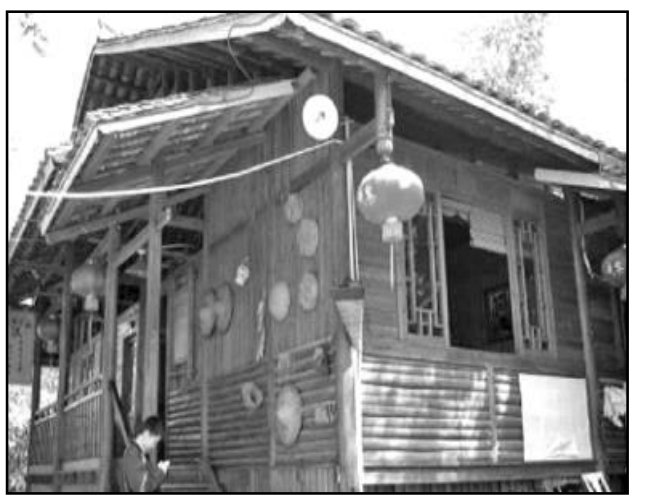

Figure 7. Wall surface ornament of living utensils.

The application of decoration parts and decoration methods of Guangxi Zhuang Nationality cultural element in landscape design is as shown in Table 2. 
Table 2. Schedule of the application of decoration parts and decoration methods of Guangxi Zhuang Nationality cultural element in landscape design.

\begin{tabular}{|c|c|c|c|}
\hline Theme & Landscape elements & Decorative objects & Decoration method \\
\hline Local material & Wood and stone material & $\mathrm{B} 1 、 \mathrm{~B} 2 、 \mathrm{~B} 3 、 \mathrm{~B} 5$ & Paste \\
\hline $\begin{array}{l}\text { Decoration } \\
\text { pattern }\end{array}$ & $\begin{array}{l}\text { Zhuang brocade, Huashan cliff } \\
\text { painting, garment, bronze drum, big- } \\
\text { leaf hydrangea and other pattern } \\
\text { ornaments. }\end{array}$ & $\begin{array}{l}\mathrm{B} 1 、 \mathrm{~B} 2 、 \mathrm{~B} 3 、 \mathrm{~B} 5 、 \\
\mathrm{~B} 15\end{array}$ & $\begin{array}{l}\text { Colored painting, wall } \\
\text { painting, wood sculpture, } \\
\text { lime sculpture, porcelain } \\
\text { attachment or direct } \\
\text { drawing. }\end{array}$ \\
\hline Utensil & $\begin{array}{l}\text { Rain hat, cloak, dustpan, etc. } \\
\text { Common living utensils. }\end{array}$ & $\mathrm{B} 1 、 \mathrm{~B} 2 、 \mathrm{~B} 3 、 \mathrm{~B} 4$ & Direct suspension \\
\hline Text & Zhuang language & $\mathrm{B} 8 、 \mathrm{~B} 11 、 \mathrm{~B} 13 、 \mathrm{~B} 15$ & $\begin{array}{l}\text { Wood sculpture, stone } \\
\text { sculpture and brick } \\
\text { sculpture } \\
\text { Colored drawing }\end{array}$ \\
\hline Color & $\begin{array}{l}\text { Five-colored rice, garment and Zhuang } \\
\text { brocade } \\
\text { Color of big-leaf hydrangea }\end{array}$ & $\begin{array}{l}\mathrm{B} 1 、 \mathrm{~B} 2 、 \mathrm{~B} 3 、 \mathrm{~B} 5 、 \\
\mathrm{~B} 8 、 \mathrm{~B} 11 、 \mathrm{~B} 15\end{array}$ & $\begin{array}{l}\text { Direct application and } \\
\text { colored drawing }\end{array}$ \\
\hline $\begin{array}{l}\text { Musical } \\
\text { instruments }\end{array}$ & $\begin{array}{l}\text { Bronze drum, ginger drum, Ma Guhu } \\
\text { Huluhu, etc. }\end{array}$ & B3、B4 & $\begin{array}{l}\text { Wood sculpture, stone } \\
\text { sculpture and brick } \\
\text { sculpture } \\
\text { Direct suspension }\end{array}$ \\
\hline Literature & Folk songs, legends, stories, poetry & $\begin{array}{l}\mathrm{B} 1 、 \mathrm{~B} 2 、 \mathrm{~B} 3 、 \mathrm{~B} 4 、 \\
\mathrm{~B} 15\end{array}$ & $\begin{array}{l}\text { Inscribed boards and } \\
\text { couplets }\end{array}$ \\
\hline Totemism & $\begin{array}{l}\text { Frogs, snakes, birds, chicken, cattle, } \\
\text { etc. } \\
\text { Totem worship objects }\end{array}$ & $\mathrm{B} 1 、 \mathrm{~B} 2 、 \mathrm{~B} 3 、 \mathrm{~B} 4$ & $\begin{array}{l}\text { Wood sculpture, stone } \\
\text { sculpture and brick } \\
\text { sculpture }\end{array}$ \\
\hline
\end{tabular}

\section{Conclusion}

This article obtains the application of traditional cultural element in the modern garden landscape design based on the relation of cultural element and landscape design, which provide a guidance ideology for the application of cultural element in Guangxi minorities in the modern landscape design. And then, it makes an analysis on the features of incorporation for cultural element in Guangxi minorities with the modern landscape design, and finds that the features of deconstruction and combination of cultural element in Guangxi minorities and modern landscape design mainly includes the subjective epistemology, living practicality, natural simulation and abstracted artistic imagination. Finally, it focuses on the research of application of cultural element in Guangxi Zhuang Nationality in the modern landscape design, and finds the derivation and reconstruction of Zhuang nationality cultural element in landscape design application, as well as the application of decoration parts and decoration methods of Guangxi Zhuang Nationality cultural element in landscape design. This article appeals the society to protect the minorities culture in Guangxi, positively abstract the reconstructed culture element for application in the actual production construction to make contributions to the inheritance and promotion of traditional culture.

\section{Acknowledgement}

This paper is supported by the Humanities \& Social Sciences Project of Educational Commission of Guangxi Province of China, "Research on the Value and Application of Cultural Element of Guangxi Minorities in Modern Landscape Design"(SK13LX512).

\section{References}

1. Lu Zongye, etc. Research on the application of totem culture of Guangxi minorities in artistic design industry of back bay economy region [J]. Popular Science \& Technology, 2014, 16(177):229-231.

2. Li Hongjian. Brief discussion on inheritance of Guangxi ethnic element in modern environmental artistic design [J]. Higher Vocational Education-Journal of Tianjin Vocational College, 2013, 22(1): 85-87.

3. Xiao Wanjuan etc. Research on the application of cultural element of Guangxi Zhuang Nationality in region characteristics of garden building [J]. Heilongjiang Agricultural Science, 2013, (5):89-93.

4. Zhang Jing, etc. Application of Chinese traditional cultural element in modern garden landscape design [J]. Research on Modern City, 2014, (6):46-50.

5. Bai Quangui, etc. Overview of Chinese Traditional Culture [M]. Zhengzhou: Zhengzhou University Press, 2003.

6. Zhang Kaizhi. Chinese Traditional Culture [M]. Beijing: Higher Education Press, 2006.

7. Lin Wei. Incorporation Research on the Chinese Traditional Cultural Element and Modern Design [D]. Wuxi: Jiangnan University, 2008.

8. Zhang Ming. Deconstruction and combination of cultural element of Guangxi Minorities and modern sculpture [J]. Artistic Theory, 2010, (9):190-191.

9. Li Ning, etc. Design and discussion on characteristic small garden ornaments in Yi Nationality of Yunnan Chuxiong [J]. Planner. 2008, 24(9):39-41. 